\title{
Systematized Becker Nevus in a female
}

\section{Krishna Deb Barman}

Department of Skin and Venereal Disease, Maulana Azad Medical College, New Delhi, India.

*Corresponding Author: Barman, K.D. Department of Skin and Venereal Disease, Maulana Azad Medical College, New Delhi, India. Tel: 9968604371; E-mail: kdebbarman@yahoo.com

\begin{abstract}
Becker's melanosis, also known as Becker nevus, is a relatively common, singular, cutaneous hamartoma, which is classically characterized by a unilateral hyperpigmented, hypertrichotic patch on the upper trunk or proximal upper extremities, with its onset during the peripubertal years in young males. A 19- year-old female patient had multiple becker nevi at right arm, right mid back and left knee area. Histopathology from all the lesions was compatible with Becker's nevus. Thus we herein report a very rare presentation of systematized Becker melanosis of atypical morphology at atypical sites in a female patient.
\end{abstract}

Keywords: Becker nevus; Female; Atypical lesion; Atypical site

\section{Introduction}

Becker's naevus (pigmented hairy epidermal naevus), a variety of epidermal naevus, is present in about $0.5 \%$ of young men. It is about 5 times more frequent in males than in females. Characteristically, it is a unilateral single lesion present on shoulder upper arm, anterior chest or scapular region in males, appearing during adolescence. Becker nevus is uncommon in females, atypical lesions and multiple sites are more uncommon. We report here a rare case of systematized Becker's naevi with 3 distinct lesions present on different sites with atypical morphology.

\section{Case Report}

A 19-year-old female patient presented to us for asymptomatic three brown colored lesions over the body that she noticed since five years. The asymptomatic mild hyperpigmented lesions first appeared during her adolescence which gradually increased in size, pigmentation and hair. No other significant history was present.

On cutaneous examination, three hyper-chromic brown colored macules with well-defined, irregular borders of size varying from $6 \times 5 \mathrm{~cm}$ to $10 \times 8 \mathrm{~cm}$ were found in the right arm region (lateral aspect), right mid back area and left knee joint (Figure 1). Only lesion on right arm region was partially covered by dark coarse hairs. No hypertrichosis was found on any other lesions. None of these macules are having acne or any other lesions. Thorough physical examination did not reveal any neurological or musculoskeletal defect. A clinical diagnosis of Becker nevus was made.
Received date: July 23, 2015

Accepted date: Sep 09, 2015

Published date: Sep 12, 2015

Citation: Barman, K.D. Systematized Becker Nevus in a female. (2015) J Dermatol Skin Biol 1(1): 2021.

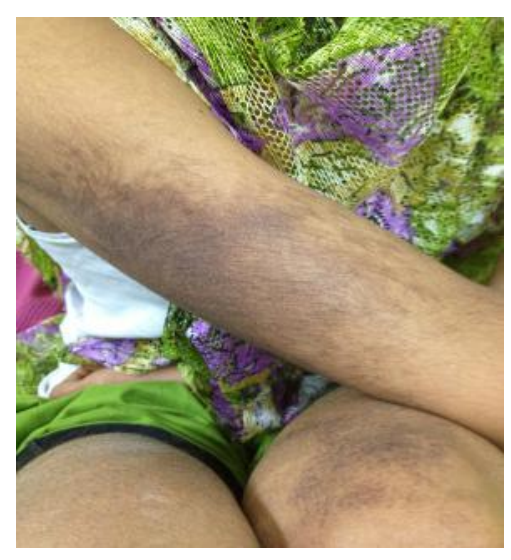

Figure 1: Hyperpigmented macules with hypertrichosis on left knee joint and right arm (outer aspect); without hypertrichosis

Histopathology carried from all three sites showed moderate acanthosis, hyperpigmentation of the basal layer with coarse granules of melanin, presence of melanophages in the papillary dermis and hyperplasia of the arrector pili muscle, compatible with Becker's nevus (Figure 2) and revealed no underlying smooth muscle prolifer- 
ation. Routine investigations were within normal limits. Systemic investigations including radiological revealed no noncutaneous abnormalities.

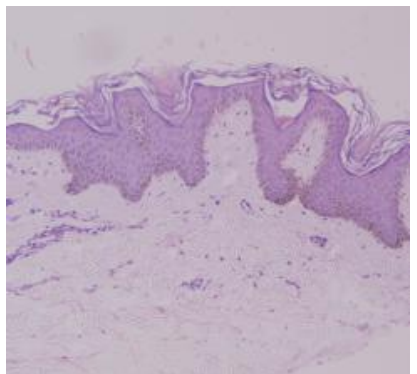

Figure 2: Histopathologic section showing moderate acanthosis, hyperpigmentation of the basal layer with coarse granules of melanin, presence of melanophages in the papillary dermis and hyperplasia of the arrector pili muscle at back ( $\mathrm{H}$ and $\mathrm{E}$, original magnification $\bullet 40)$.

\section{Discussion}

Becker's nevus (BN) as described by Becker in 1949 is a cutaneous hamartoma characterized by circumscribed hyperpigmentation with hypertrichosis ${ }^{[1]}$. Becker melanosis is thought to be an androgen-dependent lesion with increased androgen sensitivity and receptor density within the lesion. Due to this, it is much more common in males $(5: 1)$ and in adolescence ${ }^{[1]}$. It is commonly located over the trunk, including the scapular regions, shoulders, and anterior chest. Other areas are less commonly involved. An extensive search of the literature has revealed only two case of single lesion of becker nevus reported on right ${ }^{[2]}$ and left knee joint ${ }^{[3]}$.

Hypertrichosis is less prominent in this patient as seen only in one lesion. It is generally seen that Becker melanosis in women is less conspicuous with comparatively less or absent hypertrichosis and less intense hyper-pigmentation than lesions in men, presumably due to relatively less circulating androgens ${ }^{[4]}$, leading to the failure of a diagnosis of Becker's melanosis.

There are very few reports in the literature of multiple Becker nevi in the same individual. Multiple lesions are reported generally in association with Becker nevus syndrome or as bilateral symmetrical presentation ${ }^{[5-8]}$. Khaitan et al reported seven becker nevi in a 28-year-old male at sites chest, abdomen, back and right groin, extending on to the right thigh, both knees and anterior aspect of both legs, left arm and forearm ${ }^{[9]}$. Three becker nevi are reported at bilateral pre tibial and right forearm area associated with dysmorphic features and neurological abnormalities by Schepis, C. et al ${ }^{[10]}$. John et al also reported the multiple becker nevi at different locations in 14 year old female patient ${ }^{[11]}$.
Various noncutaneous abnormalities have been described in association with BN, especially unilateral hypoplasia of the breast in the females. Aplasia of the ipsilateral pectoralis major muscle, ipsilateral limb shortening, localized lipoatrophy, spina bifida, scoliosis, pectus carinatum, congenital adrenal hyperplasia and an accessory scrotum had also been found to be associated $^{[7]}$. In this patient, no such abnormalities were found even in the presence of multiple nevi. Although atypical features are found which are atypical sites and less hypertrichosis.

\section{Conclusion}

Thus we herein report a very rare presentation of non-syndromic systematized Becker melanosis of atypical morphology at atypical sites in a female patient. Our case is presented to emphasize the fact that in a female patient, Becker's melanosis should be rule out even if multiple lesions are present at atypical sites even without hypertrichosis.

\section{References}

1. Moss, C., Shahidullah H. Naevi and other developmental defects. (2010) Textbook of dermatology 8th edn 17.

2. Hsu, S., Chen, J.Y., Subrt, P. Becker's melanosis in a woman. (2001) J Am Acad Dermatol 45(6suppl): S195-S196.

3. Manoj, J., Kaliyadan, F., Hiran, K.R. Atypical presentation of Becker's melanosis. (2011) Indian Dermatol Online J 2(1): 42-43.

4. Happle, R., Koopman, R.J. Becker nevus syndrome. (1997) Am J Med Genet 68(3): 357-361.

5. Bansal, R., Sen, R. Bilateral Becker's nevi. (2008) Indian J Dermatol Venereol Leprol 74(1): 73.

6. Grim, K.D., Wasko, C.A. Symmetrical bilateral Becker melanosis: A rare presentation. (2009) Dermatol Online J 15(12): 1. 7. Khatami, A., Seradj, M.H., Gorouhi, F., et al. Giant bilateral becker nevus: a rare presentation. (2008) Pediatr Dermatol 25(1): 47-51.

8. Ferreira, M.J., Bajanca, R., Fiadeiro, T. Congenital melanosis and hypertrichosis in bilateral distribution. (1998) Pediatr Dermatol 15(4): 290-292.

9. Khaitan, B.K., Manchanda, Y., Mittal, R., et al. Multiple Becker's naevi: a rare presentation. (2001) Acta Derm Venereol 81(5): 374-375.

10. Schepis, C., Lentini, M., Failla, P., et al. An unusual presentation of Becker Nevus. (2010) Eur J Dermatol 20(4): 522-523. 11. Joh, G.Y., Lee, A.Y., Youn, J.I., et al. A multiple and extensive becker nevus. (1984) Korean J of Dermatology 22(6): 664667. 